\title{
Insights from zebrafish deficiency models to understand the impact of local thyroid hormone regulator action on early development
}

\author{
Pieter Vancamp ${ }^{1}$, Anne M. Houbrechts ${ }^{1}$, Veerle M. Darras* \\ KU Leuven, Laboratory of Comparative Endocrinology, Department of Biology, B-3000 Leuven, Belgium
}

\section{A R T I C L E I N F O}

\section{Keywords:}

Zebrafish

Thyroid hormones

Development

Deficiency models

Endocrine disrupting chemicals

\begin{abstract}
A B S T R A C T
Thyroid hormones (THs) stimulate and coordinate a wide range of processes to ensure normal development, mainly by binding of the most active $\mathrm{TH} 3,5,3^{\prime}$-triiodothyronine $\left(\mathrm{T}_{3}\right)$ to nuclear receptors resulting in changes in gene transcription. Local TH action is monitored at three distinct levels by different types of regulators: transmembrane transporters (TH influx and efflux), deiodinases (TH activation and inactivation) and nuclear receptors (TH signalling). Since TH regulators are strongly conserved among vertebrate species, the externally and rapidly developing zebrafish (Danio rerio) has become one of the favourite models to study their role in $\mathrm{TH}-$ dependent development. Most regulators are expressed in zebrafish from early stages in development in a dynamic and tissue-specific pattern. Transient or permanent disruption of a given regulator severely perturbs development of multiple organs. These zebrafish deficiency models help to explain why, next to overall hypo-/ hyperthyroidism, inactivating mutations in the genes encoding TH regulators such as MCT8 and THRA/B have irreversible adverse effects on human development. Zebrafish are also increasingly used as a high-throughput model to assess the toxicity of various xenobiotics and their impact on development. While adverse effects on TH metabolism and gene expression have been shown, information on direct interaction with TH regulators is scarce, albeit essential to fully understand their mechanism of action. For the future, the combination of novel gene silencing tools, fluorescent reporter lines and (single-cell) transcriptomics holds promise for new zebrafish models to further elucidate the role of each $\mathrm{TH}$ regulator in vertebrate development.
\end{abstract}

\section{Introduction - Facing new challenges in thyroid research}

The thyroid gland is one of the most ancient endocrine glands in vertebrate evolution and its products, the thyroid hormones (THs), are crucial factors for a variety of biological processes. The development, growth and functioning of many organs throughout the vertebrate body relies on adequate TH levels supplied via the circulation (Crockford, 2009). The production of the main $\mathrm{TH} 3,5,3^{\prime}, 5^{\prime}$-tetraiodothyronine (thyroxine, $\mathrm{T}_{4}$ ) is maintained by sufficient iodine uptake and a proper functioning hypothalamus-pituitary-thyroid (HPT) axis. In peripheral organs, the local concentration of the bioactive 3,5,3'-triiodothyronine $\left(\mathrm{T}_{3}\right)$ is adjusted relatively independent of the circulating TH levels through the interaction of transmembrane transporters, mediating cellular TH influx and efflux, and the intracellular deiodinase enzymes. In all vertebrates, deiodinase type 2 (DIO2) activates $\mathrm{T}_{4}$ into $\mathrm{T}_{3}$, and DIO3 inactivates $\mathrm{T}_{3}$ into 3,3'-diiodothyronine $\left(\mathrm{T}_{2}\right)$. DIO1 on the other hand performs both reactions, albeit with lower efficiency (Bianco and Kim, 2006; Darras and Van Herck, 2012). The intracellular availability of
$\mathrm{T}_{3}$ determines the fraction of $\mathrm{T}_{3}$-bound $\mathrm{TH}$ receptors ultimately resulting in transcriptional activation or repression of numerous genes in a time- and cell-specific fashion (Grontved et al., 2015). Vertebratewide studies have confirmed that this regulatory system is evolutionary conserved from fish to humans (Holzer et al., 2017; Porazzi et al., 2009).

Clinical data convincingly show that both maternal hypothyroidism (TH shortage) and hyperthyroidism (TH excess) negatively, and sometimes irreversibly affect the development and function of many organs, in particular the central nervous system (CNS). Major causes for dysfunction of the maternal thyroid gland have been known for long and include iodine deficiency and auto-immune disease (Poppe et al., 2008; Zimmermann and Boelaert, 2015). More recently there is growing evidence that a variety of endocrine disrupting chemicals (EDCs) also disturb maternal TH production with adverse effects for the developing embryo/foetus (Ghassabian and Trasande, 2018). The existence of various regulators of $\mathrm{TH}$ action at the peripheral level has brought forth additional challenges in thyroid research, in particular within the

\footnotetext{
* Corresponding author at: Laboratory of Comparative Endocrinology, Naamsestraat 61, P.O. Box 2464, B-3000 Leuven, Belgium.

E-mail address: veerle.darras@bio.kuleuven.be (V.M. Darras).

${ }^{1}$ Shared first author.
} 
context of development. Mutations have been identified in some of the human genes encoding the regulators of local $\mathrm{T}_{3}$ availability as well as the TH receptors. Each of them is associated with a unique but complicated phenotype, of which the underlying mechanisms remain enigmatic (Dumitrescu and Refetoff, 2013). Suitable animal models are a key factor in elucidating how inactivating mutations or xenobiotics interfering with these local regulators may disrupt early development in humans as well as vertebrates in general.

\section{The zebrafish as a suitable model to study local TH regulators}

The zebrafish (Danio rerio) is a freshwater teleost belonging to the Cyprinid family. The rapid external development, early-life transparency, cost-effective breeding and husbandry of this small-sized vertebrate make it a suitable model for developmental and toxicological studies (Roper and Tanguay, 2018). The archetypical brain shares the basic anatomical-physiological features with that of mammals, and relatively complex behaviours have been described which can be assessed using various behavioural assays (Kalueff et al., 2014a,b). The completely sequenced genome revealed $70 \%$ homology with the human nucleotide sequence, and as much as $84 \%$ of genes related to human diseases share an orthologue in zebrafish (Howe et al., 2013). Furthermore, next-generation methods for gene manipulation facilitate gene function studies (see for instance (Huang et al., 2011; Meng et al., 2008; Varshney et al., 2015), and new high-resolution imaging techniques allow to track and examine development in astonishing detail (Stewart et al., 2014).

As in all vertebrates, TH production in zebrafish is controlled by the HPT axis, with the exception that the thyroid follicles do not form a compact gland but are dispersed in the branchial region surrounding the ventral aorta, which is typical for teleosts (Alt et al., 2006). TH uptake by peripheral organs is facilitated by transmembrane $\mathrm{TH}$ transporters, of which monocarboxylate transporter 8 (Mct8) is currently the only one functionally characterised in zebrafish, having high $\mathrm{T}_{3}$ affinity at rearing temperature (Arjona et al., 2011). Other, secondary TH transporters, including Mct10 and organic anion transporting polypetide $1 \mathrm{c} 1$ (Oatp1c1) are expressed as well, and are probably also involved in TH exchange between tissues and circulation, as they do in other vertebrates (Zada et al., 2017). Also, the three types of deiodinases are present in zebrafish, but due to a whole-genome duplication Dio3 has two paralogues, with Dio3b having a predominant role over Dio3a (Guo et al., 2014; Heijlen et al., 2014). The thra gene is also duplicated (Takayama et al., 2008). The thraa gene encodes a short and a long TH receptor $\alpha 1$ isoform (zTR $\alpha 1 \mathrm{~S}$ and zTR $\alpha 1 \mathrm{~L}$, respectively), of which zTR $\alpha 1 S$ is highly homologous to human TH receptor $\alpha 1$. thrab encodes TH receptor $\alpha \beta$ (zTR $\alpha \beta$ ) which lacks transactivation activity. The thrb gene was not duplicated and encodes three isoforms, a short and a long TH receptor $\beta 1$ (zTR $\beta 1 S$ and zTR $\beta 1 \mathrm{~L}$, respectively) and TH receptor $\beta 2$ (zTRß2) (Darras et al., 2011; Marelli et al., 2016).

Due to its rapid and external development, zebrafish has been and still is one of the favourite vertebrate models for developmental biology. Moreover, the simplicity to knock down or knock out the expression of a specific gene during development has really boosted its popularity as a model to study gene function. With the increasing awareness of the potential hazard of xenobiotics for development, it has also become one of the models for high-throughput screening of chemicals for toxicity. The Fish Embryo Test (FET, OECD test guideline 236) is a standardized and validated test to assess acute toxicity of compounds in zebrafish. In general, different doses of a particular compound are administered around 2 hours post fertilisation ( $2 \mathrm{hpf}$ ), followed by daily monitoring of survival and developmental parameters. Finally, organ structure and function as well as behavioural performance are assessed between 120 and 168 hpf (Braunbeck et al., 2015; Busquet et al., 2014). Data retrieved from these experiments enable to establish dose-response relationships and early-life developmental toxicity of a compound in a fast and reproducible way. In addition, transgenic fluorescent zebrafish have been generated as reporter lines for evaluating EDC toxicity (Dai et al., 2014), and recently a method was developed to fluorescently visualise intrafollicular TH concentrations to assess direct effects of EDCs on TH production (Rehberger et al., 2018).

\section{Distribution of local TH regulators in the developing zebrafish}

The regulators of $\mathrm{TH}$ availability and $\mathrm{TH}$ receptors are present in zebrafish from very early stages onwards (Heijlen et al., 2013). Detailed information regarding their dynamic distribution in the embryonic, juvenile and adult stages can be found in (Heijlen et al., 2013; Houbrechts et al., 2016a; Marelli et al., 2016; Takayama et al., 2008; Zada et al., 2017). For the purpose of this review, we mainly discuss the expression patterns of TH regulators in the developing HPT axis and the CNS which are amongst the most TH-sensitive organs in vertebrates, and are particularly relevant for studying the effects of $\mathrm{TH}$ regulator deficiency as well as EDC toxicology.

The HPT axis of zebrafish develops and matures during the 3-day embryonic development, and the bulk of THs is of maternal origin, deposited in the egg yolk, prior to the moment when the thyrocytes start to produce endogenous THs at approximately 60-72 hpf (Porazzi et al., 2009). As in most vertebrates, fish eggs generally contain more $T_{4}$ than $\mathrm{T}_{3}$ but there is considerable variation between and even within species (Power et al., 2001). The same is true for zebrafish where measurements of the $T_{4} / T_{3}$ ratio varied from 5:1 (Walpita et al., 2007) and 4:1 (Chang et al., 2012) to 1:3 (Mukhi et al., 2007). dio1, dio3a and dio $3 b$ are highly expressed during early stages, as observed from 2 to 5 hpf in the hypothalamic region, probably preventing premature $\mathrm{T}_{3}$-dependent stimulation of neurogenesis and neuronal differentiation. From $24 \mathrm{hpf}$ onwards, dio2, thra and thrb mRNA expression increases, suggesting an important role for $\mathrm{T}_{3}$ in neurogenesis and differentiation to fine-tune the set point of the adult HPT axis. Enrichment of thrb, dio2 and $m c t 8$ in the adenohypophysis from 48 hpf onwards indicates that the thyrotropes in the developing pituitary possess the necessary machinery to 'sense' TH levels and adjust thyrotropin (Tsh) expression accordingly. The HPT axis is fully functional around the time of hatching (Darras et al., 2015; Heijlen et al., 2014; Liu and Chan, 2002; Tonyushkina et al., 2014; Vergauwen et al., 2018; Walpita et al., 2007).

thraa is highly expressed throughout the CNS between 24 and 48 hpf, while thrb is more restricted to specific regions such as the retina (Marelli et al., 2016; Takayama et al., 2008). mct8 as well as the deiodinases are abundantly present in the CNS (whole brain, spinal cord and retina), notochord, blood/lymph vessels and blood-brainbarrier at least until $168 \mathrm{hpf}$ (Campinho et al., 2014; Vatine et al., 2013). The peak of mct8 expression in blood/lymph vessels at $48 \mathrm{hpf}$ indicates its essential early function in TH exchange at the blood-brain barrier (Campinho et al., 2014; Vatine et al., 2013; Zada et al., 2014). oatp1c1 is also associated with blood vessels, while $m c t 10$ is nearly absent in the brain (Zada et al., 2017). dio1 and dio2 are expressed throughout the brain and the eye from 12 hpf onwards (Heijlen et al., 2013) while $d i o 3 a / b$ are only weakly expressed, implying a TH-activating environment in brain cells from then on (Guo et al., 2014).

Two important conclusions can be drawn from the dynamic expression pattern of these TH regulators. First of all, their early presence in a tissue-specific fashion indicates that $\mathrm{T}_{3}$ action occurs prior to HPT axis maturation and endogenous $\mathrm{TH}$ production. This corresponds to observations in other vertebrates including humans, and puts emphasis on the importance of maternally derived THs during the first stages of development (Bernal, 2017; Fini et al., 2012; Van Herck et al., 2015). Secondly, tissues and organs are able to autonomously regulate their $\mathrm{TH}$ concentrations from early development. The $\mathrm{T}_{3}$-induced gene repertoire among organs, tissues or even cells is therefore adjusted depending on the need at a given time point in development. Consequently, any discordance in $\mathrm{TH}$ levels and/or timing of local $\mathrm{T}_{3}$ action can delay, accelerate or perturb development. This increases the risk of disrupting 
the cyto-architectural organisation of a specific organ or tissue during critical time windows, possibly affecting both its short- and long-term function. This could have persistent and detrimental effects on fitnessrelated parameters. To understand the exact role of a specific TH regulator and its contribution to normal development, deficiency models have been generated by selectively silencing genes in a transient or permanent manner.

\section{Zebrafish deficiency models: Elucidating the function of a specific TH regulator}

The role of THs in zebrafish development was originally studied using goitrogens, which biochemically block TH synthesis in thyrocytes, and induce a hypothyroid state. Perchlorate, methimazole and phenylthiourea are the three most commonly used chemicals to determine the effects of hypothyroidism on general development and THsensitive organs. Overall, the phenotype is similar across studies and comprises decreased body length and weight, delayed swim bladder inflation, reduced motility, diminished eye/lens size, and a femaleskewed sex ratio (Elsalini and Rohr, 2003; Liu et al., 2008; Mukhi et al., 2007; Reider and Connaughton, 2014, 2015; Sharma and Patino, 2013; Sharma et al., 2016). While these studies provide important insights to evaluate the consequences of a severe $\mathrm{TH}$ shortage during development, the toxicity of the chemicals used also generates a risk for non-TH-related side-effects. In some of the studies, this was taken into account by performing rescue experiments with TH supplementation to show the specificity of the observed changes (Brown, 1997; Li et al., 2012; Sharma et al., 2016). However, these goitrogens act on the whole-body level and therefore do not allow to unravel the role of a single TH regulator at the cellular level. Their role within thyroid signalling during zebrafish development could not be assessed until the introduction of antisense morpholino oligonucleotides (MOs). These short synthetic oligonucleotides induce a gene-specific, transient knockdown (KD) by either translational blocking or alternative splicing via complementary base pairing (Bedell et al., 2011; Bill et al., 2009). This easy way of generating deficiency models caused a revolution in zebrafish research starting around the year 2000 (Heasman, 2002), but it still lasted several years before this technique was applied to study the function of $\mathrm{TH}$ regulators.

The first TH-related MO studies were performed on deiodinases by our research group (Walpita et al., 2009). KD of Dio1 alone did not induce any apparent effects on development, while Dio2-KD decreased pigmentation and otic vesicle length at $24 \mathrm{hpf}$, and delayed swim bladder inflation in larvae (Heijlen et al., 2013; Walpita et al., 2009). Combined Dio1 + Dio2-KD resulted in an even more severe phenotype (Walpita et al., 2010). Moreover, retinal lamination was disrupted and the majority of cone photoreceptors was lost at $72 \mathrm{hpf}$. These larvae also showed decreased growth, delayed swim bladder inflation, an abnormal light response and reduced motility at $96 \mathrm{hpf}$ (Bagci et al., 2015; Houbrechts et al., 2016b). Since Dio1 seemed only crucial under Dio2-depleted conditions, it was concluded that Dio2 is the predominant TH activator in zebrafish (Walpita et al., 2010). Dio3b-KD zebrafish also displayed decreased growth, impaired swim bladder inflation, reduced motility, and eye defects, which were more prominent and persistent than after silencing of the activating deiodinases. These abnormalities could be attributed to a hyperthyroid state, since exogenous $\mathrm{T}_{3}$ supplementation to wild-type embryos mimicked the observed phenotype. Furthermore, MO specificity was confirmed via rescue experiments with human DIO3 mRNA (Heijlen et al., 2014; Houbrechts et al., 2016b).

To overcome the major limitation of the MO technique, being the restricted time window of gene silencing (typically up to $120 \mathrm{hpf}$ ), researchers are now prompted to use current methods for genome editing. Zinc finger nucleases (ZFNs) were the first generation of tools to induce permanent and heritable mutations in zebrafish DNA, followed by transcription activator-like effector nucleases (TALENs) and most
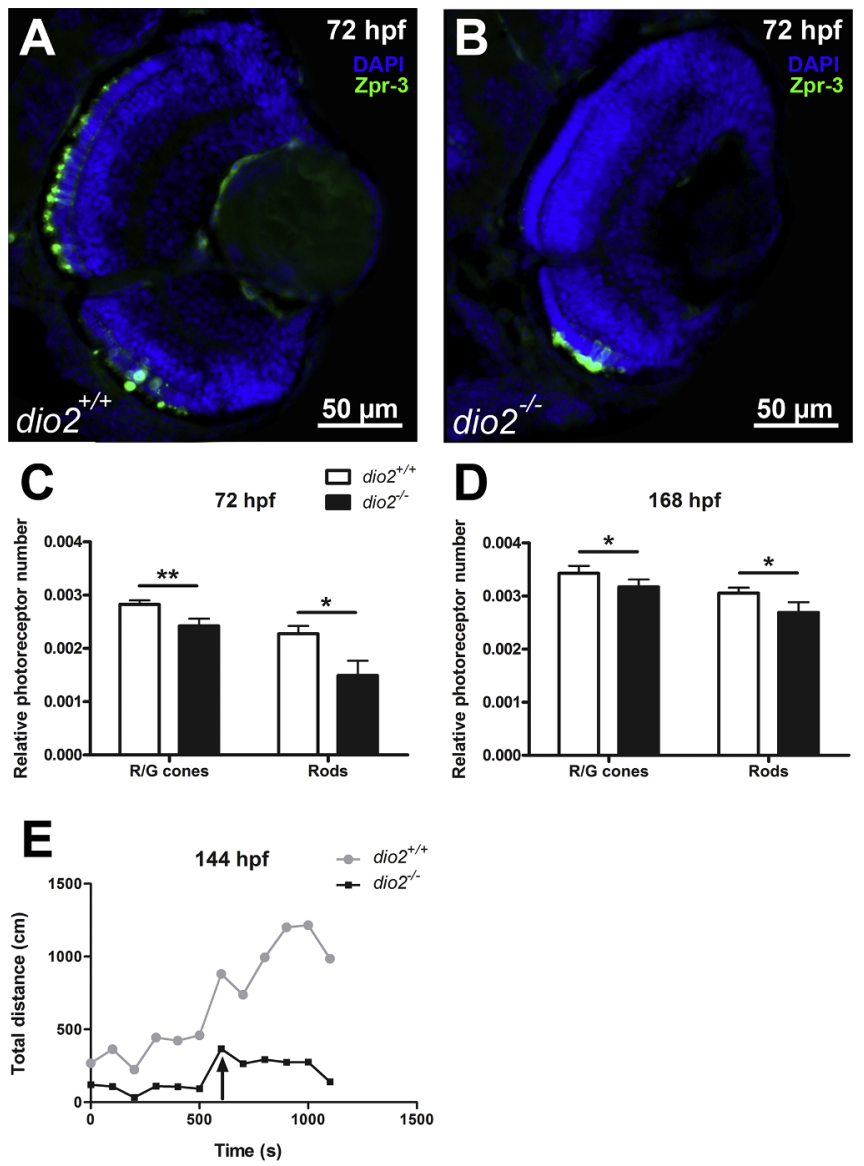

Fig. 1. The effect of permanent deiodinase type 2 deficiency on early zebrafish eye development. (A,B) Immunohistochemical staining for a rod photoreceptor marker (Zpr-3) on cryosections of the eye of (A) dio $2^{+/+}$and (B) dio $2^{-/-}$fish at $72 \mathrm{hpf}$. (C,D) Data for relative cone/rod number (expressed per retinal surface area) are shown as mean + SEM ( $\mathrm{n} \geq 7$ per group) at $72 \mathrm{hpf}$ and $168 \mathrm{hpf}$. $\mathrm{R} / \mathrm{G}$ cones: red/green cone photoreceptors were stained for the marker Zpr-1. Differences between genotypes per photoreceptor type were analyzed by unpaired Student's $t$ test. ${ }^{*} \mathrm{P}<0.05 ;{ }^{* * *} \mathrm{P}<0.01$. (E) Light response test measuring the total distance in large movements during 20 min in the dark. A $1 \mathrm{~s}$ light flash (black arrow) was given to the larvae after 10 min of dark habituation and their response was recorded. Overall, dio $2^{-/-}$larvae moved considerably less than $d i o 2^{+/+}$larvae and their response to the light was less strong. Moreover, the duration of the response was reduced in $d i o 2^{-/-}$fish, returning faster to pre-stimulation levels.

recently the Clustered Regularly Interspaced Short Palindromic Repeats (CRISPR)/Cas9 system (Huang et al., 2011; Meng et al., 2008; Varshney et al., 2015). The high efficiency and specificity of these methods in combination with the short generation time of zebrafish, allows relatively easy and cost-efficient generation of mutant lines. Our research group used the ZFN technology to generate the dio $2^{-/-}$zebrafish (Houbrechts et al., 2016a). Early development was clearly perturbed in these animals, similar as in Dio2 morphants, although slightly more severe. The mutants exhibited an aberrant light response at $144 \mathrm{hpf}$, probably due to a partial loss of their photoreceptors, and/or their reduced locomotor activity (Fig. 1). Other defects between 24 and 168 hpf included smaller eyes and ears, growth deficiency and aberrant swim bladder inflation. We also started studying the long-term effects and found that permanent Dio2 deficiency hampered growth and especially reproduction (Houbrechts et al., 2016a). Hence, Dio2 deficiency from early-life stages onwards has detrimental consequences that persist throughout adulthood.

Data on the role of TH receptors in zebrafish is more scarce and is so far limited to MO-based studies. They are particularly interesting to 


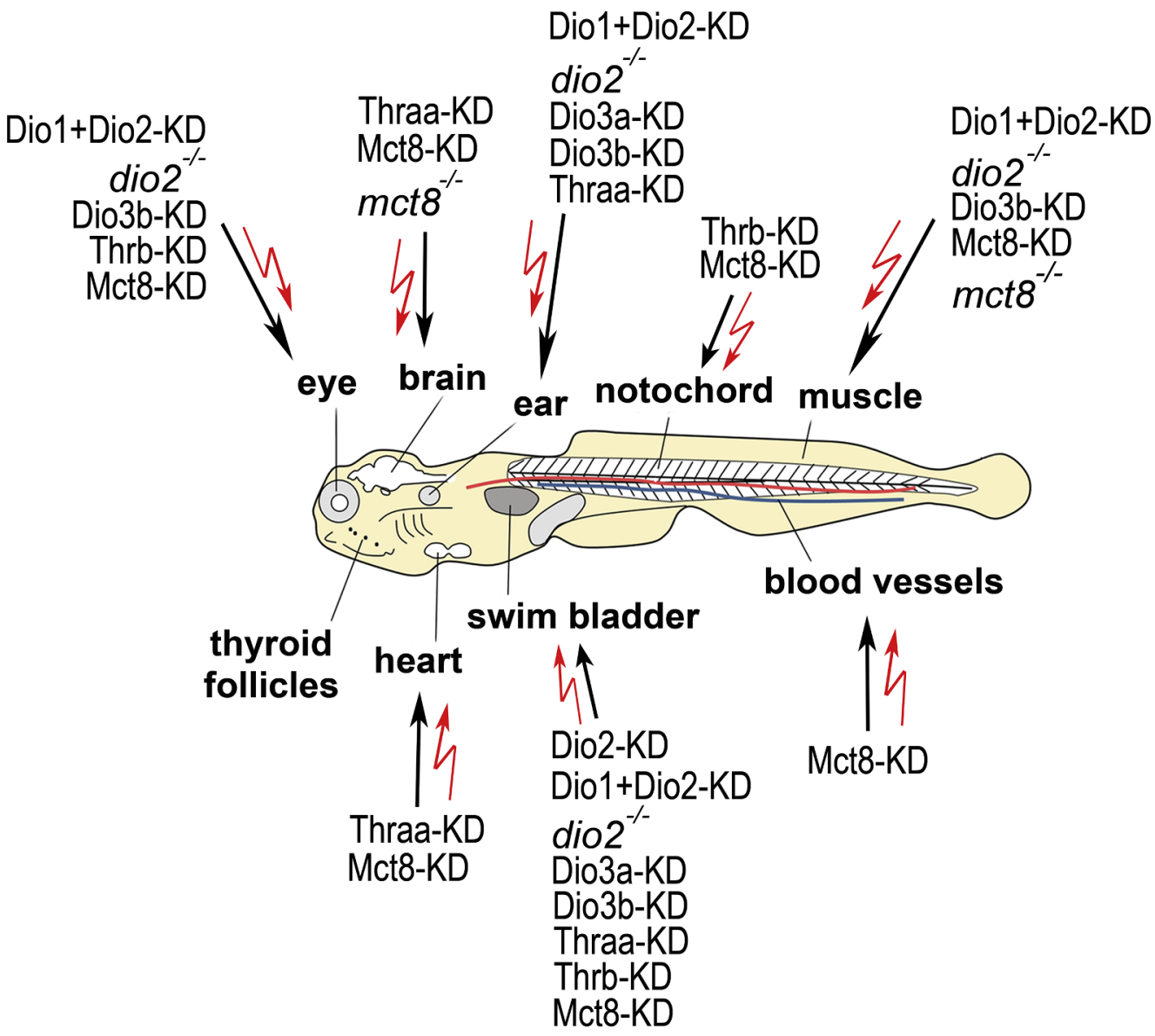

Fig. 2. Summary of the described zebrafish deficiency models for different $\mathrm{TH}$ regulators and their effect on organ development (indicated by the arrow). Note that the development of almost every $\mathrm{TH}$ sensitive organ is affected by the loss of many different regulators. Dio2-KD: deiodinase type 2 knockdown; dio $2^{-/-}$: deiodinase type 2 knockout; Dio1 + Dio2-KD: deiodinase type 1 + deiodinase type 2 co-knockdown; Dio3a-KD: deiodinase type 3a knockdown; Dio3b-KD: deiodinase type $3 \mathrm{~b}$ knockdown; Thraa-KD: thyroid hormone receptor $\alpha$ knockdown; Thrb-KD: thyroid hormone receptor $\beta$ knockdown; Mct8KD: monocarboxylate transporter 8 knockdown; $m c t 8^{-/-}$: monocarboxylate transporter 8 knockout. study the aetiology and underlying mechanisms of some human diseases. In comparison to the deiodinases, where no fully inactivating mutations in the human DIO genes have been described so far, TH receptor mutations are linked to the so-called Syndromes of $\mathrm{TH}$ Resistance as people with an inactive THRA or THRB gene suffer from reduced responsiveness of tissues to TH action (Refetoff et al., 2014). The Thraa-KD and Thrb-KD zebrafish phenotypes are very similar, showing hypopigmentation, growth delay, increased otic vesicle length, and neither swim bladder inflation nor development of pectoral fins was observed between 24 and 96 hpf. Thraa-KD fish additionally had a smaller head and cardiac oedema, while Thrb-KD fish showed deranged retinal lamination and notochord defects (Marelli et al., 2016). Severe heart problems were also observed in wild-type zebrafish embryos following injection with mutated human TR $\alpha$ mRNA (Marelli et al., 2017).

In regard to understanding the human Allan-Herndon-Dudley syndrome (AHDS), which is characterized by loss-of-function mutations in the SLC16A2 gene encoding MCT8, the zebrafish model plays an important role. AHDS patients are thyrotoxic in circulation although the CNS shows clear signs of hypothyroidism, the latter leading to severe psychomotor retardation (Dumitrescu et al., 2004; Friesema et al., 2006; Lopez-Espindola et al., 2014). While the Mct8 knockout (KO) mouse model lacks gross neuronal deficits (Dumitrescu et al., 2006), these phenotypical characteristics are evident in zebrafish with Mct8 disruption. Induction of Mct8-KD by MO injection resulted in reduced eye and brain size, a curved body axis due to a deformed spinal cord, pericardial oedema and reduced locomotor activity at $120 \mathrm{hpf}$ (Campinho et al., 2014; de Vrieze et al., 2014; Vatine et al., 2013). While one study did not report defects in the vascular system (Vatine et al 2013), others found poor vascularisation, especially in the brain (Campinho et al., 2014; de Vrieze et al., 2014). Furthermore, the expression level of several TH-responsive genes was variably affected.
The ZFN technology was subsequently used by Zada and coworkers to generate $m c t 8^{-1-}$ zebrafish. These mutants were viable and fertile, but larvae displayed reduced locomotor activity similar to Mct8 morphants. They reacted abnormally to light/dark stimuli, and showed an increased sleep time and more frequent sleep/wake transitions (Zada et al., 2014). The CNS contained fewer oligodendrocytes, and a correspondingly hypomyelinated state in the brain similar to AHDS patients. Strikingly, more Schwann cells were observed in the peripheral nervous system (Lopez-Espindola et al., 2014; Zada et al., 2016, 2014). Interestingly, these $m c t 8^{-/-}$zebrafish were the first permanent deficiency model to be used in a detailed transcriptome study. Results showed literally hundreds of differentially expressed genes at $25 \mathrm{hpf}$, associated with multiple biological pathways (Silva et al., 2017). These measurements were performed on whole zebrafish and analysis of isolated tissues might reveal even stronger effects. Anyway, the similarity between the Mct8 mutant zebrafish and AHDS is striking, and confirms the pivotal role of Mct8 as a facilitator of TH uptake from early stages of development. $m c t 8^{-/-}$zebrafish are therefore applicable to search and test potential clinical treatments, and are amenable for large-scale drug screens.

It is clear that disruption of TH signalling from embryonic stages onwards negatively affects zebrafish development (Fig. 2). The similarity and severity of the phenotypes across all these deficiency models suggests that redundancy is limited, and possible compensatory mechanisms cannot fully rescue the loss of one TH regulator. Moreover, local increases and decreases in TH concentrations are both harmful, indicating that certain organs are extremely sensitive to slightly altered $\mathrm{TH}$ levels, and that tipping the balance towards either end results in adverse outcomes. Unfortunately, studies on these regulator deficiency models have mostly been limited to very early stages of zebrafish development, while it is equally important to understand their long-term consequences for adult life stages. 


\section{The impact of EDCs on local TH regulators in zebrafish development}

The aforementioned zebrafish deficiency models clearly demonstrate that correct $\mathrm{TH}$ signalling depends on the combined effort of adequate $\mathrm{TH}$ production, and multiple $\mathrm{TH}$ regulators at the peripheral level to ensure proper tissue and organ development. EDCs mimicking $\mathrm{TH}$ structure are often able to interact with more than one level in this cascade, resulting in a mosaic phenotype. EDCs are therefore a growing concern for wildlife and human health, in particular with regard to early life stages which are extremely sensitive to endocrine disruption (Ghassabian and Trasande, 2018; Preau et al., 2015). EDCs are considered as one of the reasons for the increased prevalence of neurological disorders such as autism spectrum disorder and attention deficit/ hyperactivity disorder (Korevaar et al., 2016; Modesto et al., 2015; Morreale de Escobar et al., 2004). However, the mechanistic link between EDC exposure, local TH signalling and (neuro)developmental defects is currently poorly understood, although crucial to better predict the risk associated with a specific EDC (Schug et al., 2015).

Zebrafish have become a popular model to evaluate the toxicity of many EDCs. Embryonic and larval zebrafish exposed to low, environmentally relevant doses of EDCs among which bisphenols, polychlorinated bisphenyls (PCBs), phthalates, (poly)brominated flame retardants ((P)BDEs), and organic pesticides induce a wide array of developmental abnormalities (Dai et al., 2014; Jarque and Pina, 2014). The phenotype often comprises craniofacial malformations, altered neurogenesis, reduced axonal growth, impaired eye morphogenesis and poor swim bladder inflation, resulting in altered motility, disrupted visual function, fertility problems and even decreased survival rates in juvenile and adult zebrafish (see for instance (Chen et al., 2017; Lam et al., 2011; Macaulay et al., 2015, 2017; Noyes et al., 2013; Qiu et al., 2016; Tse et al., 2013)). Up till now, these studies mainly investigated how EDCs interact with specific targets of the central HPT axis and TH transport in the circulation. However, whether they impact the local function of the deiodinases, TH receptors and TH transporters during zebrafish/vertebrate development remains obscure, even though these regulators are increasingly considered as important targets of EDCs (Boas et al., 2012; Ghassabian and Trasande, 2018).

In vitro studies in mammalian and human cell lines have indicated that EDCs can directly act as agonists or antagonists of the TH receptors, but can also inhibit co-repressor interaction or TH receptor dimerization, and consequently disrupt the expression of TH-responsive genes necessary for developmental events (Boas et al., 2012; Kitamura et al., 2005; Miyazaki et al., 2008; Moriyama et al., 2002; Zoeller et al., 2005). Since the TH receptor protein domains in vertebrates are conserved and the sequence of the ligand-binding domain in zebrafish is 90-95\% homologous to the human orthologue (Marelli et al., 2016), one might speculate that mammalian and non-mammalian TH receptors do not differ from one another with regard to EDC affinity. Kollitz and coworkers assessed this hypothesis and determined how three wellknown brominated contaminants interfere with human and zebrafish TH receptor $\beta$ (Kollitz et al., 2018). The TH receptor $\beta$ of both species effectively bound each of the three tested EDCs, but the zebrafish TH receptor $\beta$ showed a somewhat higher affinity for 2,4,6-trichlorophenol and 2,4,6-trifluorophenol, while the human TH receptor $\beta$ preferred bisphenol $\mathrm{A}$ as a ligand. This confirms that in general data on EDC-TH receptor $\beta$ interactions retrieved from zebrafish studies can be extrapolated to the human situation, but also reminds us to keep in mind that small variations in the affinity for certain contaminants may be present (Kollitz et al., 2018).

Some studies have also shown that the expression of TH receptor $\beta$ can be altered by EDC exposure in zebrafish. Early life exposure to the frequently tested hydroxylated PBDE congener 6-hydroxy-2,2',4',4'tetrabromodiphenyl ether (6-OH-BDE-47) resulted in reduced thrb expression. Many of its deleterious effects on development could almost completely be rescued by combined overexpression of thrb during embryonic stages (Dong et al., 2014; Macaulay et al., 2015; Wang et al., 2018). This suggests that still enough intracellular $T_{3}$ is present to bind to the TH receptor $\beta$ and recover TH-responsive gene expression, or else that the presence of the unliganded $\mathrm{TH}$ receptor $\beta$ is necessary to repress premature expression of some TH-responsive genes for correct development.

With regard to the deiodinases, zebrafish studies so far only provide data on changes in their expression levels following in vivo exposure, making it difficult to interpret whether EDCs also directly affect deiodinase activity. For example, a low-dose exposure to (P)BDEs in embryonic stages only, increased the expression of dio1 and dio2 mRNA in juvenile zebrafish (Dong et al., 2013). The changes in deiodinase mRNA expression may however be indirect as a compensatory response to combat the lowered TH plasma levels caused by EDC interference with the central HPT axis (Jarque and Pina, 2014), consistent with the effects of hypothyroidism on dio2 expression (Van der Geyten et al., 2001). Correspondingly, one of our dio $2^{-/-}$zebrafish lines, expressing a nonfunctional enzyme, also showed increased dio2 mRNA expression in muscles and liver in response to the decreased $\mathrm{T}_{3}$ levels in circulation (Houbrechts et al., 2016a).

In vitro studies using mammalian cell lines have shown that some EDCs can directly interact with deiodinase activity. PBDEs and their hydroxylated derivatives were shown to be competitive inhibitors of DIO2 activity in human primary astrocytes. Moreover they also decreased DIO2 expression and enhanced post-translational degradation (Roberts et al., 2015), indicating that an EDC might interfere with deiodinases at multiple levels. Some in vitro and in vivo data is also available showing inhibitory effects on liver DIO1 activity (Aufmkolk et al., 1986; Butt et al., 2011; Ferreira et al., 2002; Schmutzler et al., 2004). These data stress the fact that we also need to test for direct effects of EDCs on deiodinase activity in zebrafish. A first step would be to make use of zebrafish-derived cell lines and test deiodinase activity following EDC exposure in vitro. For instance, a stable adult zebrafish liver-derived cell line ZF-L is available (Ghosh et al., 1994), as well as other zebrafish embryo-derived cell lines (Choorapoikayil et al., 2013; Lakra et al., 2011).

Whether or not EDCs also affect transmembrane TH transport in zebrafish, or any vertebrate for that matter, is currently unknown. The hydrophobic binding pocket of MCT8 has a high affinity for THs (Groeneweg et al., 2017; Kinne et al., 2010) but given their structure, it would not be surprising that some EDCs also compete with substrate binding at this site. Protein modelling predicts that halogenated compounds might be taken up by TH transporters like MCT8 (Ungati et al., 2018), making these transport proteins candidates via which EDCs could enter cells. On the other hand, they could also completely block TH influx and efflux if the binding is more persistent, and thereby compromise the supply of THs for deiodinases and TH receptors. Which of the two mechanisms might occur, depends on the biochemical properties of the EDC itself, and its specific interaction with the ligand binding domain. Moreover, it seems that the conformation of the ligand binding domain has evolved within each $\mathrm{TH}$ regulator protein family, resulting in specific interactions (Schweizer et al., 2014). This suggests that while some compounds that compete with TH binding to serum proteins or deiodinases do not affect MCT8 transport function (Kinne et al., 2010), others probably will, as shown for silychristin, a naturallyoccurring flavonoid extracted from milk thistle that specifically inhibits MCT8 in mammalian cells (Johannes et al., 2016). Given the important role of Mct8 in TH transport across the blood-brain barrier and neural cells in zebrafish development (Campinho et al., 2014, Zada et al., 2014), it is certainly relevant to include Mct8 as well as other transporters in zebrafish EDC assays. Similar to the deiodinases, the relation between EDC exposure and TH transport should be first assessed in vitro to get an idea of which compounds are likely candidates to have an effect in vivo. 


\section{Potential challenges facing zebrafish thyroid research}

The zebrafish has become a widely-used model organism in thyroid research, delivering essential insights in the role of peripheral TH regulators, and contributing to a rapidly expanding amount of studies regarding the interaction of EDCs with thyroid homeostasis (Garcia et al., 2016; Horzmann and Freeman, 2018; Zada et al., 2017). While later life stages (i.e. juvenile and adult) have occasionally been incorporated as end points in basic and toxicological research, the long-term consequences of TH regulator deficiency have not been thoroughly investigated. Indeed, new complications can arise later in life while being unnoticed at early-life stages, and could affect fitness-related parameters. Future studies should include detailed analysis of the juvenile/ adult phenotype in permanent knockout models, as for example the already available $m c t 8^{-/-}$fish where research has so far been restricted to embryonic and larval stages only. However, this should also be done after knocking down a specific $\mathrm{TH}$ regulator exclusively during a restricted early period, which is easily achievable using the MO-based technique. This would provide valuable information in relation to the life-long consequences of transient disturbances in TH signalling during human development.

While numerous developmental advantages are associated with this model organism, the small size might also pose a disadvantage. Most analyses are performed on whole body extracts of embryos or larvae, obscuring the potential local variations occurring in separate organs. Our transcriptome analysis of Dio1 + Dio2 co-KD and Dio3b-KD larvae carried out separately on head, trunk and tail at $72 \mathrm{hpf}$ clearly showed the importance of regional differences (Bagci et al., 2015). Moreover, in a follow-up study we performed qPCR analysis on isolated eye samples of 72-hpf-old larvae, showing even more convincing data (Houbrechts et al., 2016a). This clearly emphasizes the need to address the local aspect during early stages, a feature that may become more feasible by, for instance, crossing regulator-deficient zebrafish lines with transgenic reporter lines allowing to visualize fluorescently labelled organs or cell types.

Zebrafish has become one of the most popular models to assess the toxic effects of EDCs, but insights into their direct interactions with the local TH signalling network remain scarce. In vitro data is completely lacking for the zebrafish model, and in vivo research is mostly limited to expression studies, making it difficult to find out whether the effect of an EDC on a specific TH regulator is direct or not. Again, most studies chose early larval stages as the end point of in vivo analysis, but it should be reconsidered whether this is sufficient to draw conclusions on the persistency of EDC-related effects, and their long-term consequences for adult life functions.

The zebrafish has certainly proven its usefulness as a thyroid-related human disease model, as shown for example for AHDS and syndromes of TH Resistance. The identification of novel mutations or activity reducing polymorphisms (as seen e.g. in the DIO2 Thr92Ala point mutation) in other regulators will surely benefit from the generation of additional deficiency models to investigate their phenotypes and underlying mechanisms, providing a platform for potential drug testing and treatment options.

\section{Declaration of interest}

None.

\section{References}

Alt, B., Reibe, S., Feitosa, N.M., Elsalini, O.A., Wendl, T., Rohr, K.B., 2006. Analysis of origin and growth of the thyroid gland in zebrafish. Dev. Dyn. Off. Publicat. Am. Associat. Anatom. 235, 1872-1883.

Arjona, F.J., de Vrieze, E., Visser, T.J., Flik, G., Klaren, P.H., 2011. Identification and functional characterization of zebrafish solute carrier Slc16a2 (Mct8) as a thyroid hormone membrane transporter. Endocrinology 152, 5065-5073.

Auf'mkolk, M., Koehrle, J., Hesch, R.D., Cody, V., 1986. Inhibition of rat liver iodothyronine deiodinase. Interaction of aurones with the iodothyronine ligandbinding site. J. Biol. Chem. 261, 11623-11630.

Bagci, E., Heijlen, M., Vergauwen, L., Hagenaars, A., Houbrechts, A.M., Esguerra, C.V., Blust, R., Darras, V.M., Knapen, D., 2015. Deiodinase Knockdown during early Zebrafish development affects growth, development, energy metabolism, motility and phototransduction. PloS one 10.

Bedell, V.M., Westcot, S.E., Ekker, S.C., 2011. Lessons from morpholino-based screening in zebrafish. Brief Funct. Genom. 10, 181-188.

Bernal, J., 2017. Thyroid hormone regulated genes in cerebral cortex development. J. Endocrinol. 232, R83-R97.

Bianco, A.C., Kim, B.W., 2006. Deiodinases: implications of the local control of thyroid hormone action. J. Clin. Investig. 116, 2571-2579.

Bill, B.R., Petzold, A.M., Clark, K.J., Schimmenti, L.A., Ekker, S.C., 2009. A primer for morpholino use in zebrafish. Zebrafish 6, 69-77.

Boas, M., Feldt-Rasmussen, U., Main, K.M., 2012. Thyroid effects of endocrine disrupting chemicals. Mol. Cell. Endocrinol. 355, 240-248.

Braunbeck, T., Kais, B., Lammer, E., Otte, J., Schneider, K., Stengel, D., Strecker, R., 2015 The fish embryo test (FET): origin, applications, and future. Environ. Sci. Pollut. Res. Int. $22,16247-16261$.

Brown, D.D., 1997. The role of thyroid hormone in zebrafish and axolotl development. PNAS 94, 13011-13016.

Busquet, F., Strecker, R., Rawlings, J.M., Belanger, S.E., Braunbeck, T., Carr, G.J., Cenijn, P., Fochtman, P., Gourmelon, A., Hubler, N., Kleensang, A., Knobel, M., Kussatz, C., Legler, J., Lillicrap, A., Martinez-Jeronimo, F., Polleichtner, C., Rzodeczko, H., Salinas, E., Schneider, K.E., Scholz, S., van den Brandhof, E.J., van der Ven, L.T., Walter-Rohde, S., Weigt, S., Witters, H., Halder, M., 2014. OECD validation study to assess intra- and inter-laboratory reproducibility of the zebrafish embryo toxicity test for acute aquatic toxicity testing. Regulat. Toxicol. Pharmacol.: RTP 69, 496-511.

Butt, C.M., Wang, D., Stapleton, H.M., 2011. Halogenated phenolic contaminants inhibit the in vitro activity of the thyroid-regulating deiodinases in human liver. Toxicol. Sci.: Off. J. Soc. Toxicol. 124, 339-347.

Campinho, M.A., Saraiva, J., Florindo, C., Power, D.M., 2014. Maternal thyroid hormones are essential for neural development in zebrafish. Mol.Endocrinol. me20141032.

Chang, J., Wang, M., Gui, W., Zhao, Y., Yu, L., Zhu, G., 2012. Changes in thyroid hormone levels during zebrafish development. Zool. Sci. 29, 181-184.

Chen, J., Saili, K.S., Liu, Y., Li, L., Zhao, Y., Jia, Y., Bai, C., Tanguay, R.L., Dong, Q., Huang, C., 2017. Developmental bisphenol A exposure impairs sperm function and reproduction in zebrafish. Chemosphere 169, 262-270.

Choorapoikayil, S., Overvoorde, J., den Hertog, J., 2013. Deriving cell lines from zebrafish embryos and tumors. Zebrafish 10, 316-325.

Crockford, S.J., 2009. Evolutionary roots of iodine and thyroid hormones in cell-cell signaling. Integr. Comp. Biol. 49, 155-166.

Dai, Y.J., Jia, Y.F., Chen, N., Bian, W.P., Li, Q.K., Ma, Y.B., Chen, Y.L., Pei, D.S., 2014 Zebrafish as a model system to study toxicology. Environ. Toxicol. Chem. 33, 11-17.

Darras, V.M., Houbrechts, A.M., Van Herck, S.L., 2015. Intracellular thyroid hormone metabolism as a local regulator of nuclear thyroid hormone receptor-mediated impact on vertebrate development. BBA 1849, 130-141.

Darras, V.M., Van Herck, S.L., 2012. Iodothyronine deiodinase structure and function: from ascidians to humans. J. Endocrinol. 215, 189-206.

Darras, V.M., Van Herck, S.L., Heijlen, M., De Groef, B., 2011. Thyroid hormone receptors in two model species for vertebrate embryonic development: chicken and zebrafish. J. Thyroid Res 402320.

de Vrieze, E., van de Wiel, S.M., Zethof, J., Flik, G., Klaren, P.H., Arjona, F.J., 2014 Knockdown of monocarboxylate transporter 8 (mct8) disturbs brain development and locomotion in zebrafish. Endocrinology 155, 2320-2330.

Dong, W., Macaulay, L.J., Kwok, K.W., Hinton, D.E., Ferguson, P.L., Stapleton, H.M., 2014. The PBDE metabolite 6-OH-BDE 47 affects melanin pigmentation and THRbeta MRNA expression in the eye of zebrafish embryos. Endocrine Disruptors 2.

Dong, W., Macaulay, L.J., Kwok, K.W., Hinton, D.E., Stapleton, H.M., 2013. Using whole mount in situ hybridization to examine thyroid hormone deiodinase expression in embryonic and larval zebrafish: a tool for examining OH-BDE toxicity to early life stages. Aquat. Toxicol. 132-133, 190-199.

Dumitrescu, A.M., Liao, X.H., Best, T.B., Brockmann, K., Refetoff, S., 2004. A novel syndrome combining thyroid and neurological abnormalities is associated with mutations in a monocarboxylate transporter gene. Am. J. Hum. Genet. 74, 168-175.

Dumitrescu, A.M., Liao, X.H., Weiss, R.E., Millen, K., Refetoff, S., 2006. Tissue-specific thyroid hormone deprivation and excess in monocarboxylate transporter (mct) 8deficient mice. Endocrinology 147, 4036-4043.

Dumitrescu, A.M., Refetoff, S., 2013. The syndromes of reduced sensitivity to thyroid hormone. BBA 1830, 3987-4003.

Elsalini, O.A., Rohr, K.B., 2003. Phenylthiourea disrupts thyroid function in developing zebrafish. Dev. Genes. Evol. 212, 593-598.

Ferreira, A.C., Lisboa, P.C., Oliveira, K.J., Lima, L.P., Barros, I.A., Carvalho, D.P., 2002 Inhibition of thyroid type 1 deiodinase activity by flavonoids. Food Chem. Toxicol: Int. J. Publis. Br. Indust. Biol. Res. Associat. 40, 913-917.

Fini, J.B., Le Mevel, S., Palmier, K., Darras, V.M., Punzon, I, Richardson, S.J., ClergetFroidevaux, M.S., Demeneix, B.A., 2012. Thyroid hormone signaling in the Xenopus laevis embryo is functional and susceptible to endocrine disruption. Endocrinology $153,5068-5081$.

Friesema, E.C., Jansen, J., Heuer, H., Trajkovic, M., Bauer, K., Visser, T.J., 2006 Mechanisms of disease: psychomotor retardation and high T3 levels caused by mutations in monocarboxylate transporter 8. Nat. Clin. Pract. Endocrinol. Metab. 2, $512-523$.

Garcia, G.R., Noyes, P.D., Tanguay, R.L., 2016. Advancements in zebrafish applications for 21st century toxicology. Pharmacol. Ther. 161, 11-21.

Ghassabian, A., Trasande, L., 2018. Disruption in thyroid signaling pathway: a 
mechanism for the effect of endocrine-disrupting chemicals on child neurodevelop ment. Front. Endocrinol, 9, 204.

Ghosh, C., Zhou, Y.L., Collodi, P., 1994. Derivation and characterization of a zebrafish liver cell line. Cell Biol. Toxicol. 10, 167-176.

Groeneweg, S., Visser, W.E., Visser, T.J., 2017. Disorder of thyroid hormone transport into the tissues. Best practice \& research. Clin. Endocrinol. Metabol. 31, 241-253.

Grontved, L., Waterfall, J.J., Kim, D.W., Baek, S., Sung, M.H., Zhao, L., Park, J.W., Nielsen, R., Walker, R.L., Zhu, Y.J., Meltzer, P.S., Hager, G.L., Cheng, S.Y., 2015. Transcriptional activation by the thyroid hormone receptor through ligand-dependent receptor recruitment and chromatin remodelling. Nat. Commun. 6, 7048.

Guo, C., Chen, X., Song, H., Maynard, M.A., Zhou, Y., Lobanov, A.V., Gladyshev, V.N., Ganis, J.J., Wiley, D., Jugo, R.H., Lee, N.Y., Castroneves, L.A., Zon, L.I., Scanlan, T.S., Feldman, H.A., Huang, S.A., 2014. Intrinsic expression of a multiexon type 3 deiodinase gene controls zebrafish embryo size. Endocrinology 155, 4069-4080.

Heasman, J., 2002. Morpholino oligos: making sense of antisense? Dev. Biol. 243, 209-214.

Heijlen, M., Houbrechts, A.M., Bagci, E., Van Herck, S.L., Kersseboom, S., Esguerra, C.V., Blust, R., Visser, T.J., Knapen, D., Darras, V.M., 2014. Knockdown of type 3 iodothyronine deiodinase severely perturbs both embryonic and early larval development in zebrafish. Endocrinology 155, 1547-1559.

Heijlen, M., Houbrechts, A.M., Darras, V.M., 2013. Zebrafish as a model to study peripheral thyroid hormone metabolism in vertebrate development. Gen. Comp. Endocrinol. 188, 289-296.

Holzer, G., Roux, N., Laudet, V., 2017. Evolution of ligands, receptors and metabolizing enzymes of thyroid signaling. Mol. Cell. Endocrinol. 459, 5-13.

Horzmann, K.A., Freeman, J.L., 2018. Making waves: new developments in toxicology with the zebrafish. Toxicol. Sci.: an Off. J. Soc. Toxicol. 163, 5-12.

Houbrechts, A.M., Delarue, J., Gabriels, I.J., Sourbron, J., Darras, V.M., 2016 a. Permanent deiodinase Type 2 deficiency strongly perturbs Zebrafish development, Growth, and fertility. Endocrinology 157, 3668-3681.

Houbrechts, A.M., Vergauwen, L., Bagci, E., Van Houcke, J., Heijlen, M., Kulemeka, B., Hyde, D.R., Knapen, D., Darras, V.M., 2016b. Deiodinase knockdown affects zebrafish eye development at the level of gene expression, morphology and function. Mol. Cell. Endocrinol. 424, 81-93.

Howe, K., Clark, M.D., Torroja, C.F., Torrance, J., Berthelot, C., Muffato, M., Collins, J.E., Humphray, S., McLaren, K., Matthews, L., McLaren, S., Sealy, I., Caccamo, M., Churcher, C., Scott, C., Barrett, J.C., Koch, R., Rauch, G.J., White, S., Chow, W., Kilian, B., Quintais, L.T., Guerra-Assuncao, J.A., Zhou, Y., Gu, Y., Yen, J., Vogel, J.H., Eyre, T., Redmond, S., Banerjee, R., Chi, J., Fu, B., Langley, E., Maguire, S.F., Laird, G.K., Lloyd, D., Kenyon, E., Donaldson, S., Sehra, H., Almeida-King, J., Loveland, J., Trevanion, S., Jones, M., Quail, M., Willey, D., Hunt, A., Burton, J., Sims, S., McLay, K., Plumb, B., Davis, J., Clee, C., Oliver, K., Clark, R., Riddle, C., Elliot, D., Threadgold, G., Harden, G., Ware, D., Begum, S., Mortimore, B., Kerry, G., Heath, P., Phillimore, B., Tracey, A., Corby, N., Dunn, M., Johnson, C., Wood, J., Clark, S., Pelan, S., Griffiths, G., Smith, M., Glithero, R., Howden, P., Barker, N., Lloyd, C. Stevens, C., Harley, J., Holt, K., Panagiotidis, G., Lovell, J., Beasley, H., Henderson, C., Gordon, D., Auger, K., Wright, D., Collins, J., Raisen, C., Dyer, L., Leung, K., Robertson, L., Ambridge, K., Leongamornlert, D., McGuire, S., Gilderthorp, R. Griffiths, C., Manthravadi, D., Nichol, S., Barker, G., Whitehead, S., Kay, M., Brown, J., Murnane, C., Gray, E., Humphries, M., Sycamore, N., Barker, D., Saunders, D., Wallis, J., Babbage, A., Hammond, S., Mashreghi-Mohammadi, M., Barr, L., Martin, S., Wray, P., Ellington, A., Matthews, N., Ellwood, M., Woodmansey, R., Clark, G., Cooper, J., Tromans, A., Grafham, D., Skuce, C., Pandian, R., Andrews, R., Harrison, E., Kimberley, A., Garnett, J., Fosker, N., Hall, R., Garner, P., Kelly, D., Bird, C., Palmer, S., Gehring, I., Berger, A., Dooley, C.M., Ersan-Urun, Z., Eser, C., Geiger, H., Geisler, M., Karotki, L., Kirn, A., Konantz, J., Konantz, M., Oberlander, M., RudolphGeiger, S., Teucke, M., Lanz, C., Raddatz, G., Osoegawa, K., Zhu, B., Rapp, A., Widaa, S., Langford, C., Yang, F., Schuster, S.C., Carter, N.P., Harrow, J., Ning, Z., Herrero, J., Searle, S.M., Enright, A., Geisler, R., Plasterk, R.H., Lee, C., Westerfield, M., de Jong, P.J., Zon, L.I., Postlethwait, J.H., Nusslein-Volhard, C., Hubbard, T.J., Roest Crollius, H., Rogers, J., Stemple, D.L., 2013. The zebrafish reference genome sequence and its relationship to the human genome. Nature 496, 498-503.

Huang, P., Xiao, A., Zhou, M., Zhu, Z., Lin, S., Zhang, B., 2011. Heritable gene targeting in zebrafish using customized TALENs. Nat. Biotechnol. 29, 699-700.

Jarque, S., Pina, B., 2014. Deiodinases and thyroid metabolism disruption in teleost fish. Environ. Res. 135, 361-375.

Johannes, J., Jayarama-Naidu, R., Meyer, F., Wirth, E.K., Schweizer, U., Schomburg, L., Kohrle, J., Renko, K., 2016. Silychristin, a flavonolignan derived from the milk thistle, Is a potent inhibitor of the thyroid hormone transporter MCT8. Endocrinology 157, 1694-1701.

Kalueff, A.V., Echevarria, D.J., Stewart, A.M., 2014a. Gaining translational momentum: more zebrafish models for neuroscience research. Prog. Neuro-Psychopharmacol. Biol. Psychiat. 55, 1-6.

Kalueff, A.V., Stewart, A.M., Gerlai, R., 2014b. Zebrafish as an emerging model for studying complex brain disorders. Trends Pharmacol. Sci. 35, 63-75.

Kinne, A., Kleinau, G., Hoefig, C.S., Gruters, A., Kohrle, J., Krause, G., Schweizer, U., 2010. Essential molecular determinants for thyroid hormone transport and first structural implications for monocarboxylate transporter 8. J. Biol. Chem. 285, 28054-28063.

Kitamura, S., Kato, T., Iida, M., Jinno, N., Suzuki, T., Ohta, S., Fujimoto, N., Hanada, H., Kashiwagi, K., Kashiwagi, A., 2005. Anti-thyroid hormonal activity of tetrabromobisphenol A, a flame retardant, and related compounds: Affinity to the mammalian thyroid hormone receptor, and effect on tadpole metamorphosis. Life Sci. 76, $1589-1601$.

Kollitz, E.M., De Carbonnel, L., Stapleton, H.M., Lee Ferguson, P., 2018. The affinity of brominated phenolic compounds for human and zebrafish thyroid receptor beta:
Influence of chemical structure. Toxicol. Sci.: Official J. Soc. Toxicol. 163, 226-239. Korevaar, T.I., Muetzel, R., Medici, M., Chaker, L., Jaddoe, V.W., de Rijke, Y.B., Steegers, E.A., Visser, T.J., White, T., Tiemeier, H., Peeters, R.P., 2016. Association of maternal thyroid function during early pregnancy with offspring IQ and brain morphology in childhood: a population-based prospective cohort study. Lancet Diab. Endocrinol. 4 , 35-43.

Lakra, W.S., Swaminathan, T.R., Joy, K.P., 2011. Development, characterization, conservation and storage of fish cell lines: a review. Fish Physiol. Biochem. 37, 1-20.

Lam, S.H., Hlaing, M.M., Zhang, X., Yan, C., Duan, Z., Zhu, L., Ung, C.Y., Mathavan, S., Ong, C.N., Gong, Z., 2011. Toxicogenomic and phenotypic analyses of bisphenol-A early-life exposure toxicity in zebrafish. PLoS ONE 6 e28273.

Li, Z., Ptak, D., Zhang, L., Walls, E.K., Zhong, W., Leung, Y.F., 2012. Phenylthiourea specifically reduces zebrafish eye size. PLoS ONE 7 e40132.

Liu, F., Gentles, A., Theodorakis, C.W., 2008. Arsenate and perchlorate toxicity, growth effects, and thyroid histopathology in hypothyroid zebrafish Danio rerio. Chemosphere 71, 1369-1376.

Liu, Y.W., Chan, W.K., 2002. Thyroid hormones are important for embryonic to larval transitory phase in zebrafish. Differentiation; Res. Biol. Divers. 70, 36-45.

Lopez-Espindola, D., Morales-Bastos, C., Grijota-Martinez, C., Liao, X.H., Lev, D., Sugo, E., Verge, C.F., Refetoff, S., Bernal, J., Guadano-Ferraz, A., 2014. Mutations of the thyroid hormone transporter MCT8 cause prenatal brain damage and persistent hypomyelination. J. Clin. Endocrinol. Metabol. 99, E2799-E2804.

Macaulay, L.J., Chen, A., Rock, K.D., Dishaw, L.V., Dong, W., Hinton, D.E., Stapleton, H.M., 2015. Developmental toxicity of the PBDE metabolite 6-OH-BDE-47 in zebrafish and the potential role of thyroid receptor beta. Aquat. Toxicol. 168, 38-47.

Macaulay, L.J., Chernick, M., Chen, A., Hinton, D.E., Bailey, J.M., Kullman, S.W., Levin, E.D., Stapleton, H.M., 2017. Exposure to a PBDE/OH-BDE mixture alters juvenile zebrafish (Danio rerio) development. Environ. Toxicol. Chem. 36, 36-48.

Marelli, F., Carra, S., Agostini, M., Cotelli, F., Peeters, R., Chatterjee, K., Persani, L., 2016. Patterns of thyroid hormone receptor expression in zebrafish and generation of a novel model of resistance to thyroid hormone action. Mol. Cell. Endocrinol. 424, $102-117$.

Marelli, F., Carra, S., Rurale, G., Cotelli, F., Persani, L., 2017. In vivo functional consequences of human THRA variants expressed in the zebrafish. Thyroid: Off. J. Am. Thyroid Assoc. 27, 279-291.

Meng, X., Noyes, M.B., Zhu, L.J., Lawson, N.D., Wolfe, S.A., 2008. Targeted gene inactivation in zebrafish using engineered zinc-finger nucleases. Nat. Biotechnol. 26, 695-701.

Miyazaki, W., Iwasaki, T., Takeshita, A., Tohyama, C., Koibuchi, N., 2008. Identification of the functional domain of thyroid hormone receptor responsible for polychlorinated biphenyl-mediated suppression of its action in vitro. Environ. Health Perspect. 116, 1231-1236.

Modesto, T., Tiemeier, H., Peeters, R.P., Jaddoe, V.W., Hofman, A., Verhulst, F.C., Ghassabian, A., 2015. Maternal mild thyroid hormone insufficiency in early pregnancy and attention-deficit/hyperactivity disorder symptoms in children. JAMA Pediatr. 169, 838-845.

Moriyama, K., Tagami, T., Akamizu, T., Usui, T., Saijo, M., Kanamoto, N., Hataya, Y., Shimatsu, A., Kuzuya, H., Nakao, K., 2002. Thyroid hormone action is disrupted by bisphenol A as an antagonist. J. Clin. Endocrinol. Metabol. 87, 5185-5190.

Morreale de Escobar, G., Obregon, M.J., Escobar del Rey, F., 2004. Role of thyroid hormone during early brain development. Eur. J. Endocrinol. 151 (Suppl 3), U25-U37.

Mukhi, S., Torres, L., Patino, R., 2007. Effects of larval-juvenile treatment with perchlorate and co-treatment with thyroxine on zebrafish sex ratios. Gen. Comp. Endocrinol. 150, 486-494.

Noyes, P.D., Lema, S.C., Macaulay, L.J., Douglas, N.K., Stapleton, H.M., 2013. Low leve exposure to the flame retardant BDE-209 reduces thyroid hormone levels and disrupts thyroid signaling in fathead minnows. Environ. Sci. Technol. 47, 10012-10021.

Poppe, K., Velkeniers, B., Glinoer, D., 2008. The role of thyroid autoimmunity in fertility and pregnancy. Nat. Clin. Pract. Endocrinol. Metab. 4, 394-405.

Porazzi, P., Calebiro, D., Benato, F., Tiso, N., Persani, L., 2009. Thyroid gland development and function in the zebrafish model. Mol. Cell. Endocrinol. 312, 14-23.

Power, D.M., Llewellyn, L., Faustino, M., Nowell, M.A., Bjornsson, B.T., Einarsdottir, I.E., Canario, A.V., Sweeney, G.E., 2001. Thyroid hormones in growth and development of fish. Comparative biochemistry and physiology. Toxicol. Pharmacol. CBP 130, 447-459.

Preau, L., Fini, J.B., Morvan-Dubois, G., Demeneix, B., 2015. Thyroid hormone signaling during early neurogenesis and its significance as a vulnerable window for endocrine disruption. Biochim. Biophys. Acta 1849, 112-121.

Qiu, W., Zhao, Y., Yang, M., Farajzadeh, M., Pan, C., Wayne, N.L., 2016. Actions of bisphenol A and bisphenol S on the reproductive neuroendocrine system during early development in Zebrafish. Endocrinology 157, 636-647.

Refetoff, S., Bassett, J.H., Beck-Peccoz, P., Bernal, J., Brent, G., Chatterjee, K., De Groot, L.J., Dumitrescu, A.M., Jameson, J.L., Kopp, P.A., Murata, Y., Persani, L., Samarut, J., Weiss, R.E., Williams, G.R., Yen, P.M., 2014. Classification and proposed nomenclature for inherited defects of thyroid hormone action, cell transport, and metabolism. J. Clin. Endocrinol. Metabol. 99, 768-770.

Rehberger, K., Baumann, L., Hecker, M., Braunbeck, T., 2018. Intrafollicular thyroid hormone staining in whole-mount zebrafish (Danio rerio) embryos for the detection of thyroid hormone synthesis disruption. Fish Physiol. Biochem. 44, 997-1010.

Reider, M., Connaughton, V.P., 2014. Effects of low-dose embryonic thyroid disruption and rearing temperature on the development of the eye and retina in zebrafish. Birth Defects Res. Part B, Dev. Reprod. Toxicol. 101, 347-354.

Reider, M., Connaughton, V.P., 2015. Developmental exposure to methimazole increases anxiety behavior in zebrafish. Behav. Neurosci. 129, 634-642.

Roberts, S.C., Bianco, A.C., Stapleton, H.M., 2015. Disruption of type 2 iodothyronine deiodinase activity in cultured human glial cells by polybrominated diphenyl ethers. 
Chem. Res. Toxicol. 28, 1265-1274.

Roper, C., Tanguay, R.L., 2018. Zebrafish as a Model for Developmental Biology and Toxicology, Handbook of Developmental Neurotoxicology, Second ed. Academic press pp. 143-151.

Schmutzler, C., Hamann, I., Hofmann, P.J., Kovacs, G., Stemmler, L., Mentrup, B., Schomburg, L., Ambrugger, P., Gruters, A., Seidlova-Wuttke, D., Jarry, H., Wuttke, W., Kohrle, J., 2004. Endocrine active compounds affect thyrotropin and thyroid hormone levels in serum as well as endpoints of thyroid hormone action in liver, heart and kidney. Toxicology 205, 95-102.

Schug, T.T., Blawas, A.M., Gray, K., Heindel, J.J., Lawler, C.P., 2015. Elucidating the links between endocrine disruptors and neurodevelopment. Endocrinology 156, 1941-1951.

Schweizer, U., Johannes, J., Bayer, D., Braun, D., 2014. Structure and function of thyroid hormone plasma membrane transporters. Eur. Thyroid J. 3, 143-153.

Sharma, P., Patino, R., 2013. Regulation of gonadal sex ratios and pubertal development by the thyroid endocrine system in zebrafish (Danio rerio). Gen. Comp. Endocrinol. 184, 111-119.

Sharma, P., Tang, S., Mayer, G.D., Patino, R., 2016. Effects of thyroid endocrine manipulation on sex-related gene expression and population sex ratios in Zebrafish. Gen. Comp. Endocrinol. 235, 38-47.

Silva, N., Louro, B., Trindade, M., Power, D.M., Campinho, M.A., 2017. Transcriptomics reveal an integrative role for maternal thyroid hormones during zebrafish embryogenesis. Sci. Rep. 7, 16657.

Stewart, A.M., Braubach, O., Spitsbergen, J., Gerlai, R., Kalueff, A.V., 2014. Zebrafish models for translational neuroscience research: from tank to bedside. Trends Neurosci. 37, 264-278.

Takayama, S., Hostick, U., Haendel, M., Eisen, J., Darimont, B., 2008. An F-domain introduced by alternative splicing regulates activity of the zebrafish thyroid hormone receptor alpha. Gen. Comp. Endocrinol. 155, 176-189.

Tonyushkina, K.N., Shen, M.C., Ortiz-Toro, T., Karlstrom, R.O., 2014. Embryonic exposure to excess thyroid hormone causes thyrotrope cell death. J. Clin. Investig. 124, 321-327.

Tse, W.K., Yeung, B.H., Wan, H.T., Wong, C.K., 2013. Early embryogenesis in zebrafish is affected by bisphenol A exposure. Biol. open 2, 466-471.

Ungati, H., Govindaraj, V., Mugesh, G., 2018. The remarkable effect of halogen substitution on the membrane transport of fluorescent molecules in living cells. Angew. Chem.

Van der Geyten, S., Segers, I., Gereben, B., Bartha, T., Rudas, P., Larsen, P.R., Kuhn, E.R., Darras, V.M., 2001. Transcriptional regulation of iodothyronine deiodinases during embryonic development. Mol. Cell. Endocrinol. 183, 1-9.

Van Herck, S.L., Delbaere, J., Bourgeois, N.M., McAllan, B.M., Richardson, S.J., Darras, V.M., 2015. Expression of thyroid hormone transporters and deiodinases at the brain barriers in the embryonic chicken: Insights into the regulation of thyroid hormone availability during neurodevelopment. Gen. Comp. Endocrinol. 214, 30-39.

Varshney, G.K., Pei, W., LaFave, M.C., Idol, J., Xu, L., Gallardo, V., Carrington, B., Bishop, K., Jones, M., Li, M., Harper, U., Huang, S.C., Prakash, A., Chen, W., Sood, R., Ledin, J., Burgess, S.M., 2015. High-throughput gene targeting and phenotyping in zebrafish using CRISPR/Cas9. Genome Res. 25, 1030-1042.

Vatine, G.D., Zada, D., Lerer-Goldshtein, T., Tovin, A., Malkinson, G., Yaniv, K. Appelbaum, L., 2013. Zebrafish as a model for monocarboxyl transporter 8-deficiency. J. Biol. Chem. 288, 169-180.

Vergauwen, L., Cavallin, J.E., Ankley, G.T., Bars, C., Gabriels, I.J., Michiels, E.D.G., Fitzpatrick, K.R., Periz-Stanacev, J., Randolph, E.C., Robinson, S.L., Saari, T.W., Schroeder, A.L., Stinckens, E., Swintek, J., Van Cruchten, S.J., Verbueken, E., Villeneuve, D.L., Knapen, D., 2018. Gene transcription ontogeny of hypothalamicpituitary-thyroid axis development in early-life stage fathead minnow and zebrafish. Gen. Comp. Endocrinol.

Walpita, C.N., Crawford, A.D., Darras, V.M., 2010. Combined antisense knockdown of type 1 and type 2 iodothyronine deiodinases disrupts embryonic development in zebrafish (Danio rerio). Gen. Comp. Endocrinol. 166, 134-141.

Walpita, C.N., Crawford, A.D., Janssens, E.D., Van der Geyten, S., Darras, V.M., 2009. Type 2 iodothyronine deiodinase is essential for thyroid hormone-dependent embryonic development and pigmentation in zebrafish. Endocrinology 150, 530-539.

Walpita, C.N., Van der Geyten, S., Rurangwa, E., Darras, V.M., 2007. The effect of 3,5,3'triiodothyronine supplementation on zebrafish (Danio rerio) embryonic development and expression of iodothyronine deiodinases and thyroid hormone receptors. Gen. Comp. Endocrinol. 152, 206-214.

Wang, F., Fang, M., Hinton, D.E., Chernick, M., Jia, S., Zhang, Y., Xie, L., Dong, W., Dong, W., 2018. Increased coiling frequency linked to apoptosis in the brain and altered thyroid signaling in zebrafish embryos (Danio rerio) exposed to the PBDE metabolite 6-OH-BDE-47. Chemosphere 198, 342-350.

Zada, D., Blitz, E., Appelbaum, L., 2017. Zebrafish - An emerging model to explore thyroid hormone transporters and psychomotor retardation. Mol. Cell. Endocrinol In press.

Zada, D., Tovin, A., Lerer-Goldshtein, T., Appelbaum, L., 2016. Pharmacological treatment and BBB-targeted genetic therapy for MCT8-dependent hypomyelination in zebrafish. Dis. Model Mechan. 9, 1339-1348.

Zada, D., Tovin, A., Lerer-Goldshtein, T., Vatine, G.D., Appelbaum, L., 2014. Altered behavioral performance and live imaging of circuit-specific neural deficiencies in a zebrafish model for psychomotor retardation. PLoS Genet. 10 e1004615.

Zimmermann, M.B., Boelaert, K., 2015. Iodine deficiency and thyroid disorders. Lancet Diab. Endocrinol. 3, 286-295.

Zoeller, R.T., Bansal, R., Parris, C., 2005. Bisphenol-A, an environmental contaminant that acts as a thyroid hormone receptor antagonist in vitro, increases serum thyroxine, and alters RC3/neurogranin expression in the developing rat brain. Endocrinology 146, 607-612. 